\title{
SIMULTANEOUS DETERMINATION OF GEMIFLOXACIN AND DIURETICS IN BULK, PHARMACEUTICAL DOSAGE FORMS AND HUMAN SERUM BY RP-HPLC
}

\author{
Najma Sultana, Sana Shamim*, Mahwish Akhtarand Somia Gul \\ Department of Pharmaceutical Chemistry, Faculty of Pharmacy, Research Institute of Pharmaceutical Sciences, University of \\ Karachi, Karachi-75270, Pakistan \\ M. Saeed Arayne \\ Department of Chemistry, University of Karachi, Pakistan
}

Recebido em 25/11/09; aceito em 16/3/10; publicado na web em 20/7/10

\begin{abstract}
An isocratic reversed phase high-performance liquid chromatographic (RP-HPLC) method has been developed for the simultaneous determination of gemifloxacin and diuretics (hydrochlorothiazide and furosemide) in bulk, dosage formulations and human serum at $232 \mathrm{~nm}$. Chromatographic separation was achieved on Purospher Start $C_{18}(250 \mathrm{~mm}$ x $4.6 \mathrm{~mm}, 5 \mu \mathrm{m})$ column using mobile phase, methanol: water: acetonitrile (70:25:5 v/v/v) adjusted to $\mathrm{pH} 3.0$ via phosphoric acid $85 \%$ having flow rate of $0.8 \mathrm{~mL} \mathrm{~min}^{-1}$ at room temperature. Calibration curves were linear over range of $0.5-10 \mu \mathrm{g} \mathrm{mL}{ }^{-1}$ with a correlation coefficient \pm 0.999 . LOD and LOQ were in the ranges of $0.75-2.56 \mu \mathrm{g} \mathrm{mL}^{-1}$. Intra and inter-run precision and accuracy results were 98.26 to 100.9 .
\end{abstract}

Keywords: gemifloxacin; diuretics; HPLC.

\section{INTRODUCTION}

Gemifloxacin (GFX) is a fourth generation fluoroquinolone antibacterial compound with enhanced affinity for bacterial topoisomerase IV and is being used for the treatment of respiratory and urinary tract infections. The compound has a broad spectrum of activity against Gram-positive and Gram-negative bacteria. ${ }^{1-3}$ It is particularly active against Gram-positive organisms including penicillin-, macrolide-, and quinolone-resistant Streptococcus pneumoniae ${ }^{4} 4$-folds more potent than moxifloxacin against $S$. pneumoniae. ${ }^{5}$ Gemifloxacin has also shown potent activity against other major pathogens involved in respiratory tract infections, including Haemophilus influenzae and Moraxella catarrhalis and the atypical organisms, Legionella pneumophila,Chlamydia spp., and Mycoplasma spp. ${ }^{6,7}$ Furthermore, the compound has shown potent activity against many organisms that cause urinary tract infections and bronchitis. ${ }^{8}$

Diuretics are widely used in the treatment of congestive heart failure and hypertension. ${ }^{9,10}$ Mostly increase urinary potassium excretion and thus can cause hypokalemia in patients with prolong use. Diuretics selected for study are hydrochlorothiazide (HCT) and furosemide (FUR) which are thiazide and loop diuretics, respectively. ${ }^{11}$

Literature survey revealed that few analytical methods have been reported for the estimation of GFX; they include high performance liquid chromatography tandem mass, ${ }^{12,13}$ microchip electrophoresis, ${ }^{14}$ chiral high-performance liquid chromatography, ${ }^{15}$ and chiral counter-current chromatography. ${ }^{16,17}$ Simple and sensitive ion-pairing spectrophotometer methods have been described for the assay of gemifloxacin mesylate by Marothu et al. ${ }^{18}$ Barbosa et al. studied dissociation constants of series of compounds including diuretics and quinolones in several acetonitrile: water mixtures. ${ }^{19}$

Work done by Sudoh et al. ${ }^{20}$ reveals that concomitant administration of furosemide and lomefloxacin increases the bioavailability of lomefloxacin by decreasing its rate of renal clearance. As quinolones, furosemide and hydrochlorthiazide, ${ }^{21}$ are reported to be excreted in urine by the renal tubular anion transport system. Therefore, in present paper, we report a simple, easy, quick and inexpensive iso-

\footnotetext{
*e-mail: ssanashamim@yahoo.com
}

cratic RP-HPLC method with ultraviolet detection at $232 \mathrm{~nm}$ for the simultaneous determination of GFX and two diuretics i.e. HCT and FUR. Simultaneous determination of both drugs is desirable as this would allow more efficient generation of clinical data and could be performed at more modest cost than separate assays. The method is equally valid for the determination in bulk materials, pharmaceutical dosage formulations and human serum. This method can be used for the quantitative analysis of diuretics and gemifloxacin alone or in combination. The low LOD and LOQ values merit the method for the determination of these drugs in clinical samples.

\section{EXPERIMENTAL}

\section{Materials and reagents}

All chemicals and reagents were of analytical grade. Gemifloxacin (purity 99.82\%) was a kind gift from PharmEvo (Pvt) Limited, Pakistan. Hydrochlorothiazide (purity 99.94\%) and furosemide (purity $99.79 \%$ ) were gifts from Zafa Pharmaceutical Laboratories (Pvt) Ltd and Sanofi Aventis (Pvt) Limited, Pakistan. HPLC grade acetonitrile, methanol and phosphoric acid were obtained from Tedia (USA) and Merck Darmstadt, Germany.

\section{Pharmaceutical dosage form}

Gemixa $^{\text {TM }}$ (Gemifloxacin 320 mg tablets by Bosch Pharmaceuticals (Pvt) Ltd), Diuza ${ }^{\mathrm{TM}}$ (Hydrochlorothiazide $25 \mathrm{mg}$ tablets by Zafa Pharmaceutical Laboratories (Pvt) Ltd), and Lasix ${ }^{\mathrm{TM}}$ (40 mg tablets from Sanofi Aventis Pakistan Limited), were purchased from the local pharmacies (Figure 1). All these drugs had an expiry of not less than 1 year at the time of study.

\section{Instrumentation}

The HPLC system consisted of an LC-10 AT VP Shimadzu pump, SPD-10AV VP Shimadzu UV visible detector, a Purospher Start $C_{18}$ $(250 \times 4.6 \mathrm{~mm}, 5 \mu \mathrm{m})$ column was used for separation. The chromatographic system was integrated using a CBM-102 communication Bus 
<smiles>CO/N=C1\CN(c2nc3c(cc2F)c(=O)c(C(=O)O)cn3C2CC2)CC1CN</smiles>

Gemifloxacin mesylate

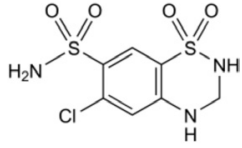

Hydrochlorothiazide

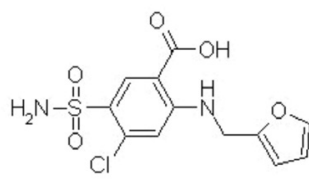

Furosemide

Figure 1. Chemical structures of Gemifloxacin mesylate, Hydrochlorothiazide and Furosemide

Module Shimadzu with a Pentium ${ }^{\text {TM }}$ IV PC loaded with Class GC software for data acquisition. Separation was carried out under isocratic elution with methanol: water: acetonitrile (70:25:5) as mobile phase. The $\mathrm{pH}$ of the mobile phase was adjusted to 3.0 with phosphoric acid $(85 \%)$, sonicated by DGU-14 AM on-line degasser, and filtered through 0.45 -micron membrane filter. The flow rate was $0.8 \mathrm{~mL} \mathrm{~min}^{-1}$, the elution was monitored at $232 \mathrm{~nm}$, and the injection volume was $20 \mu \mathrm{L}$.

\section{Preparation of standard and sample solutions}

\section{Standard preparation}

Stock standard solutions 100 ppm of GFX, HCT and FUR were prepared in $100 \mathrm{~mL}$ mobile phase as solvent. Working solutions were prepared separately by making serial dilutions from the standard solution to obtain concentration between $0.5-10,0.125-2.5$ and $0.025-0.5 \mu \mathrm{g} \mathrm{mL} \mathrm{m}^{-1}$ for GFX, HCT and FUR, respectively. These solutions were stored at $20{ }^{\circ} \mathrm{C}$. Once prepared, analyzed daily for inter and intra-day variations of the method. $20 \mu \mathrm{L}$ of these solutions were injected into LC system and chromatographed.

\section{Procedure for tablets}

Twenty tablets of each formulation were powdered finely and an amount equivalent to $10 \mathrm{mg}$ of GFX, HCT and FUR was weighed and then dissolved in the mobile phase. Solutions were then filtered through ordinary filter paper. The desired concentrations $0.5-10,0.125-2.5$ and $0.025-0.5 \mu \mathrm{g} \mathrm{mL}^{-1}$ for GFX, HCT and FUR, respectively were obtained by accurate dilution, solutions were then sonicated. Finally, all the solutions were filtered through $45-\mu \mathrm{m}$ Millipore filter, in order to separate out the insoluble excepients before chromatographed.

\section{Procedure for human serum}

Plasma samples, obtained from healthy volunteers, were collected and stored. To $1.0 \mathrm{~mL}$ of plasma, $9.0 \mathrm{~mL}$ of acetonitrile was added; the mixture was vortexed for $1 \mathrm{~min}$ and than centrifuged for 10 $\min$ at $10,000 \mathrm{rpm}$ and the supernatant was filtered by 0.45 -micron membrane filter. An aliquot of serum sample was fortified with GFX, HCT and FUR to achieve final concentration.

\section{RESULTS AND DISCUSSION}

\section{Development and optimization of isocratic HPLC conditions}

The aim of the present study was to develop a simple, isocratic, accurate and sensitive HPLC method for the simultaneous deter- mination of GFX, HCT and FUR. A UV scan showed a maximal absorbance at or near $232 \mathrm{~nm}$. Initial method development was conducted on a Purospher Start $C_{18}(250 \times 4.6 \mathrm{~mm}, 5 \mu \mathrm{m})$ column for separation at ambient temperature. This column provides efficient and reproducible separations of non-polar compounds while minimizing solvent usage. Initially various mobile phases were tested to obtain the best separation and resolution. The mobile phase consisting of methanol, water and acetonitrile in the ratio of $70: 25: 5, \mathrm{v} / \mathrm{v} / \mathrm{v}$ found to have good resolution. The chromatographic conditions were optimized to achieve best separation and to get best resolution between analytes and to optimize chromatographic parameters like resolution, tailing factor and retention time. The optimized conditions were reached at $\mathrm{pH} 3.0$, producing well resolved and sharp peaks for all drugs. The specificity of the method was established through the study of resolution factor of gemifloxacin peak. Peaks were identified using retention times compared with those of standards. For validation of analytical methods, the guidelines of the International Conference on the Harmonization of Technical Requirements for the Registration of Pharmaceuticals for Human Use, ${ }^{22}$ and USP $2002,{ }^{25}$ were followed for the accuracy tests, precision, specificity, linearity, work strip and robustness of the method. Retention time of GFX was $2.8 \mathrm{~min}$, HCT $3.4 \mathrm{~min}$ and FUR was $4.2 \mathrm{~min}$, at a flow rate of $0.8 \mathrm{~mL} \mathrm{~min}^{-1}$.

\section{System suitability}

It is an imperative module of method validation to make certain that the operational system is running appropriately throughout the analysis. The system was equilibrated with the initial mobile phase composition, followed by 10 injections of the same standard. These 10 consecutive injections were used to evaluate the system suitability on each day of method validation (Table 1).

Table 1. System suitability parameters of the proposed method for gemifloxacin, hydrochlorothiazide and furosemid

\begin{tabular}{lcccccc}
\hline Drugs & $\begin{array}{c}\text { Retention } \\
\text { time }\left(\mathrm{t}_{\mathrm{R}}\right)\end{array}$ & \multicolumn{6}{c}{ Capacity } & factor $\left(\mathrm{K}^{\prime}\right)$ & tor $(\mathrm{T})$ & $(\mathrm{R})$ & plates $(\mathrm{N})$ & factor $(\alpha)$ \\
\hline GFX & 2.8 & 2.4 & 1.34 & 1.47 & 1782 & 4.03 \\
HCT & 3.4 & 3.07 & 1.4 & 2.09 & 2621 & 1.28 \\
FUR & 4.2 & 3.95 & 1.5 & 2.6 & 3075 & 1.29 \\
\hline
\end{tabular}

GFX: Gemifloxacin; HCT: Hydrochlorothiazide; FUR: Furosemide

\section{Linearity}

Linearity is generally reported as the variance of the slope of the regression line. Linearity was tested with known concentrations of GFX, HCT and FUR i.e. 0.5, 1.0, 2.5, 5 and 10, 0.125, 0.25, 0.625, 1.25 and 2.5 and $0.025,0.05,0.125,0.25$ and $-0.5 \mu \mathrm{gL}^{-1}$, respectively. Five runs were performed for every concentration. Injected concentrations versus area were plotted and the correlation coefficients were calculated which are shown in Table 2.

\section{Accuracy}

The accuracy of an analytical procedure measures the closeness of measured values to the true values. It was evaluated as percentage relative error between the measured mean concentrations and taken concentrations. ${ }^{22-24}$ Minimal of 3 concentration levels covering the specified ranges were selected and three runs were performed for every concentration and then peak area was calculated as given in Table 3 . 
Table 2. Regression characteristics of the proposed method for gemifloxacin, hydrochlorothiazide and furosemide

\begin{tabular}{lccc}
\hline Drugs & GFX & HCT & FUR \\
\hline Conc. range $\left(\mu \mathrm{gL}^{-1}\right)$ & $0.5-10$ & $0.125-2.5$ & $0.025-0.5$ \\
Correlation coefficient $\left(\mathrm{r}^{2}\right)$ & 0.9992 & 0.9992 & 0.9992 \\
Standard error of estimate & 1.28 & 1.26 & 1.29 \\
Standard error & 0.82 & 0.81 & 0.83 \\
Intercept & 2.02 & 2.52 & 2.1 \\
Slope & 6020 & 5489 & 5529 \\
\hline
\end{tabular}

GFX: Gemifloxacin; HCT: Hydrochlorothiazide; FUR: Furosemide

Table 3. Accuracy of the proposed method for gemifloxacin, hydrochlorothiazide and furosemide

\begin{tabular}{lccccccc}
\hline \multirow{2}{*}{ Parameters } & $\begin{array}{c}\text { Conc. } \\
\left(\mu \mathrm{gL} \mathrm{m}^{-1}\right) \\
\text { Spiked }\end{array}$ & GFX & HCT & FUR & GFX & HCT & FUR \\
\hline Assay in bulk & 4.0 & 3.93 & 3.934 & 3.943 & 98.26 & 98.36 & 98.57 \\
& 5.0 & 4.968 & 4.968 & 4.965 & 99.37 & 99.37 & 99.3 \\
& 6.0 & 6.018 & 6.013 & 6.05 & 100.2 & 100.3 & 100.9 \\
Assay in serum & 4.0 & 3.94 & 3.94 & 3.951 & 98.46 & 98.46 & 98.62 \\
& 5.0 & 4.97 & 4.974 & 4.968 & 99.47 & 99.47 & 99.4 \\
& 6.0 & 6.02 & 6.02 & 6.057 & 100.3 & 100.3 & 100.9 \\
\hline
\end{tabular}

GFX: Gemifloxacin; HCT: Hydrochlorothiazide; FUR: Furosemide

\section{Intraday and inter-day precision}

The precision of the method was investigated with respect to repeatability. For intra-day and inter-day precision, ten samples of five concentrations were analyzed on the same day and after one day (Table 4). Generally acceptable repeatability of the results with in one day and day-to-day was observed. ${ }^{22-24}$ The precision of the method was analyzed as \% RSD throughout the linear range of concentrations.

Table 4. Inter and intra-day precision of the proposed method for gemifloxacin, hydrochlorothiazide and furosemide $(n=6)$

\begin{tabular}{lcccc}
\hline Drug & $\begin{array}{c}\text { Concentration } \\
\left(\mu \mathrm{gL}^{-1}\right)\end{array}$ & $\begin{array}{c}\text { Formulation (\%RSD) } \\
\text { Intra-day }\end{array}$ & $\begin{array}{c}\text { Serum (\%RS) } \\
\text { Inter-day } \\
\text { variations }\end{array}$ & $\begin{array}{c}\text { Intra-day } \\
\text { GFX }\end{array} 0$ \\
1 & 0.5 & 0.03 & 0.03 & 0.08 \\
& 2.5 & 0.09 & 0.05 & 0.04 \\
& 5 & 0.06 & 0.07 & 0.02 \\
HCT & 10 & 0.08 & 0.07 & 0.09 \\
& 0.125 & 0.02 & 0.05 & 0.07 \\
& 0.25 & 0.05 & 0.04 & 0.06 \\
& 0.625 & 0.01 & 0.03 & 0.09 \\
& 1.25 & 0.07 & 0.05 & 0.09 \\
FUR & 2.5 & 0.06 & 0.04 & 0.8 \\
& 0.025 & 0.02 & 0.03 & 0.06 \\
& 0.05 & 0.1 & 0.07 & 0.12 \\
& 0.125 & 0.16 & 0.05 & 0.03 \\
& 0.25 & 0.06 & 0.06 & 0.09 \\
& 0.5 & 0.02 & 0.02 & 0.03 \\
\hline
\end{tabular}

GFX: Gemifloxacin; HCT: Hydrochlorothiazide; FUR: Furosemide

\section{Robustness}

Robustness of the method was accomplished by designed modifications made to the method parameters such as composition, flow rate, $\mathrm{pH}$ of the mobile phase, detection wavelength, injection volume and column temperature (Table 5) and it was found that the \%R.S.D values did not exceed more than $2 \% .^{22-24}$

Table 5. Robustness of the proposed method

\begin{tabular}{lcccc}
\hline Factors & Level & $\mathrm{t}_{\mathrm{R}}$ & $\mathrm{k}$ & $\mathrm{T}$ \\
\hline $\mathrm{pH}$ & & & & \\
2.8 & -2 & 2.6 & 2.45 & 1.32 \\
3 & 0 & 2.8 & 2.4 & 1.34 \\
3.2 & 2 & 3 & 2.35 & 1.36 \\
Flow rate $\left(\mathrm{mL} \mathrm{min}^{-1}\right)$ & & & \\
0.6 & -2 & 3 & 2.35 & 1.36 \\
0.8 & 0 & 2.8 & 2.4 & 1.34 \\
1.2 & 2 & 2.6 & 2.45 & 1.32 \\
Percentage of methanol in mobile phase (v/v) & & \\
65 & -5 & 2.9 & 2.3 & 1.36 \\
70 & 0 & 2.8 & 2.4 & 1.34 \\
75 & 5 & 2.6 & 2.6 & 1.32 \\
\hline
\end{tabular}

\section{Limit of detection and quantitation}

The limit of detection (LOD) and limit of quantitation (LOQ) of this method were determined from the known concentrations of GFX, HCT and FUR. The LOD and LOQ for this assay were calculated from three and ten times the noise level of the response, respectively. Which are given in Table 6.

Table 6. LOD and LOQ of the proposed method for gemifloxacin, hydrochlorothiazide and furosemide

\begin{tabular}{lccc}
\hline Drugs & $\begin{array}{c}\text { Conc. } \\
\left(\mu \mathrm{g} \mathrm{mL}^{-1}\right)\end{array}$ & $\begin{array}{c}\mathrm{LOD} \\
\left(\mu \mathrm{g} \mathrm{mL}^{-1}\right)\end{array}$ & $\begin{array}{c}\mathrm{LOQ} \\
\left(\mu \mathrm{g} \mathrm{mL}^{-1}\right)\end{array}$ \\
\hline GFX & $0.5-10$ & 0.77 & 2.35 \\
HCT & $0.125-2.5$ & 0.85 & 2.56 \\
FUR & $0.025-0.5$ & 0.84 & 2.55 \\
\hline
\end{tabular}

GFX: Gemifloxacin; HCT: Hydrochlorothiazide; FUR: Furosemide; LOD: Limit of Detection; LOQ: Limit of Quantification

\section{Specificity and selectivity}

The specificity of the chromatographic method was determined to ensure separation of gemifloxacin and diuretics as shown in Figure 2. Specificity was also determined by screening four different samples of controlled human serum, which were free from interfering endogenous plasma components. Solutions of placebo, gemifloxacin and diuretics were prepared and then injected to check for interference from common excepients.

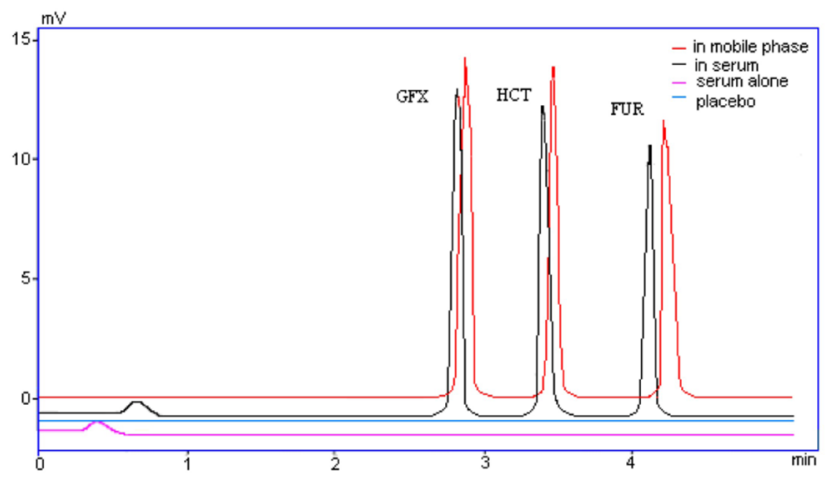

Figure 2. Chromatograms of GFX (50 ppm), HCT (12.5 ppm) and FUR (25 ppm) in mobile phase, human serum, human serum alone and placebo at $232 \mathrm{~nm}$ 


\section{Ruggedness}

The ruggedness was established by determining GFX, HCT and FUR in dosage formulation and in human serum using same and different chromatographic system and same column by different analysts on different days. The assay results indicated that the method was capable with high precision (Table 4).

\section{CONCLUSION}

A simple and reliable HPLC method for monitoring GFX, HCT and FUR in human serum and pharmaceutical dosage formulation has been developed. A fully validated RP-HPLC procedure for the assay of these drugs in bulk, tablets and human serum is described for the first time. Hence, it can be recommended for the routine quality control of these drugs, low volume of blood or plasma is needed. Simplicity of the separation procedure; shorter run time and the low volume of injection make this method suitable for quick and routine analysis. The intra-run and inter-run variability and accuracy results were also in acceptable limit. In addition, this method has the potential application to clinical research of drug combination, multi-drug pharmacokinetics and interactions.

\section{ACKNOWLEDGEMENTS}

The authors thanks to Higher Education Commission (H.E.C) of Pakistan for financial support.

\section{REFERENCES}

1. Oh, J. I.; Paek, M. J.; Ahn, M. Y.; Kim, C. Y.; Hong, C. Y.; Kim, I. C.; Kwak, J. H.; Antimicrob. Agents Chemother. 1996, 40, 1564.

2. Johnson, D. M.; Jones, R. N.; Erwin, M. E.; Diagn. Microbiol. Infect Dis. 1999, 33, 87.

3. Berry, V.; Page, R.; Satterfield, J.; Singley, C.; Straub, R.; Woodnutt, G.; J. Antimicrob. Chemother. 2000, 45, 79.

4. Hardy, D.; Amsterdam, D.; Mandell, L.; Rotstein, C.; Antimicrob. Agents Chemother. 1999, 44, 802.

5. Serkan, O.; Ther. Clin. Risk Manag. 2007, 3, 441.

6. Hannan, P.; Woodnutt, G.; Antimicrob. Agents Chemother. 2000, 45, 367.
7. Ann, A.; Elizabeth, B.; Marika, V.; Stuart, O.; Martin, J.; Christopher, W.; Ae-Jin, C.; Youn, S. C.; In-Chull, K.; Antimicrob. Agents Chemother. 2001, 45, 540.

8. Cristian, J.; Mark, G.; Int. J. Chron. Obstruct. Pulmon. Dis. 2009, 4, 291.

9. Bridges. J. W.; Chasseaud. L. F.; Progress in Drug Metabolism, Wiley and Sons: New York, 1983, vol. 7.

10. Ventura, R.; Nadal, T.; Alcalde, P.; Pascual, J. A.; Segura, J.; J. Chromatogr., A 1993, 655, 233.

11. Bertram, G.; Katzung.; Basic \& clinical pharmacology, $10^{\text {th }}$ ed., McGraw Hill, 2007.

12. Doyle, E.; Fowles, S. E.; Mc Donnell, D. F.; Carthy, M.; White, S. A.; J. Chromatogr., B 2000, 746, 191.

13. Ramji, J. V.; Austin, N. E.; Boyle, G. W.; Chalker, M. H.; Duncan, G.; Fairless, A. J.; Hollis, F. J.; Mc-Donnell, D. F.; Musick, T. J.; Shardlow, P. C.; Drug Metab. Dispos. 2001, 29, 435.

14. Seung, I. C.; Jiyeon, S.; Min, S. K.; Yong, K. K.; Doo, S. C.; J. Chromatogr., A 2004, 1055, 241.

15. Hee, J. C.; Hwan, S. C.; Sang, C. H.; Myung, H. H.; J. Sep. Sci. 2009, $32,536$.

16. Eun, S. K.; Yoo-mo, K.; Doo, S. C.; J. Chromatogr. 2004, 1045, 119.

17. Myung, H. H.; Sang, C. H.; Yoon, J. C.; Jong, S. J.; Wonjae, L.; Biomed. Chromatogr. 2002, 16, 356.

18. Marothu, V. K.; Dannana, G. S.; E-J. Chem. 2008, 5, 515.

19. Barbosa, J.; Marquis, I.; Fonrodona, G.; Barth, D.; Bergs, R.; Anal. Chim. Acta 1997, 347, 385.

20. Sudoh, T.; Fujimura, A.; Shiga, T.; Sasaki, M.; Harada, K.; Tateishi, T.; Ohashi, K.; Ebihara, A .; Eur. J. Clin. Pharmacol. 1994, 46, 267.

21. Niemeyer, C.; Hasenfu, G.; Wais, U.; Knauf, H.; Schäfer, K. M.; Mutschler, E.; Euro. J. Clinical Pharmacol. 1983, 24, 661.

22. International Conference on Hormonisation of Technical Requirements for Registration of Pharmaceuticals for Human Use, ICH Harmonised Tripartite Guideline; Validation of Analytical Procedures: Text and Methodology Q2(R 1), Complementary Guideline on Methodology dated 06 November 1996, incorporated in November 2005, London.

23. Shabir, G. A.; J. Chromatogr., A 2003, 987, 57.

24. Ermer, J.; J. Pharm. Biomed. Anal. 2001, 24, 755.

25. United States Pharmacopeia; National Formulary, Validation of Compendial Methods <1225>, Rockville, MD, 2007, p. 549. 